\section{Reports indicate that changes are needed to close the gap for Indigenous health}

To THE Editor: The summation by Russell that"the inescapable reality is that current primary care interventions are not working" 1 overlooks evidence of significant improvements in the Northern Territory. The latest "closing the gap" report indicates that the Indigenous mortality gap in the NT should close within a generation. ${ }^{2}$

Mortality among NT Indigenous adults has declined by a third since $2000 .{ }^{2}$ We attribute this positive outcome primarily to effective use of primary health care funding, which has been progressively increased and equitably distributed, since 2001. This money has funded universally adopted e-health solutions and NT key performance indicators, which drive continuous quality improvement initiatives. These are backed by common clinical guidelines, with increasing adherence rates, that are used in all Aboriginal primary health care clinics. ${ }^{3}$

The statement "ACCHOs [Aboriginal community controlled health organisations] have had little influence on the mainstream health system $^{\prime 1}$ neglects experience in the NT, where the ACCHO sector is a co-owner of the NT Medicare Local and remains a critical driver in the NT Aboriginal Health Forum (NTAHF). Now in its 15th year, the NTAHF has secured government support for community control as the preferred model for delivering Aboriginal primary health care. The ACCHO sector is also a leader in developing and using clinical guidelines, mental health services, e-health, and continuous quality improvement programs. National policy should support the expansion and enhancement of Aboriginal community controlled primary health care services.

Pasqualina M Coffey Public Health Registrar

Alex Hope Public Health Medical Officer'

John D Boffa Chief Medical Officer Public Health²
1 Public Health Unit, Aboriginal Medical Services Alliance Northern Territory, Darwin, NT.

2 Public Health Division, Central Australian Aboriginal Congress, Alice Springs, NT.

\section{alex.hope@amsant.org.au}

Competing interests: No relevant disclosures. doi: 10.5694/mjal4.00057

1 Russell L. Reports indicate that changes are needed to close the gap for Indigenous health. Med J Aust 2013; 199: 737-738.

2 COAG Reform Council. Indigenous reform 2011-12: comparing performance across Australia. Report to the Council of Australian Governments. 2013. http://www. coagreformcouncil.gov.au/sites/default/files/ files/National\%20Indigenous\%20Reform\%20 Agreement \%20-\%2030\%20April\%20 2013\%281\%29.pdf (accessed May 2014).

3 Bailie R, Si D, Dowden M, et al. Improving organisational systems for diabetes care in Australian Indigenous communities. BMC Health Serv Res 2007; 7: 67.

IN REPLY: The letter from Coffey and colleagues helps make my case that a major role for Aboriginal community controlled health organisations (ACCHOs) in providing health care to Indigenous communities makes a real difference in the effectiveness and efficiency of service delivery. However, we cannot be certain that the progress made in reducing Indigenous mortality rates in the Northern Territory is the result of better health care; it may reflect improvements in the social determinants of health, such as education, housing and community violence.

Hospital data highlight that success is still a long way off. The ratio of Indigenous to non-Indigenous agedstandardised hospital separations for the NT is 7.9, compared with 2.5 for all jurisdictions. ${ }^{1}$ There is a clear relationship between the number of primary care visits and hospitalisation for Indigenous residents of the Territory who live in remote communities. For patients with diabetes, ischaemic heart disease and renal disease, around 22 to 30 primary care visits a year are needed to reduce hospitalisations to a minimum. ${ }^{2}$ That is why an increased role for ACCHOs is one of the keys to closing the gap.

Lesley M Russell Visiting Fellow

Australian Primary Health Care Research Institute, Australian National University, Canberra, ACT.

lesley.russell@anu.edu.au
Competing interests: No relevant disclosures. doi: 10.5694/mjal4.00265

1 Australian Indigenous Health/nfoNet. Overview of Australian Indigenous health status 2012 http://www.healthinfonet.ecu.edu.au/ uploads/docs/overview_of_indigenous_ health_2012.pdf (accessed Feb 2014).

2 Zhao Y, Wright J, Guthridge S, Lawton P. The relationship between number of primary health care visits and hospitalisations: evidence from linked clinic and hospital data for remote Indigenous Australians. BMC Health Serv Res 2013; 13: 466. http://www. biomedcentral.com/1472-6963/13/466 (accessed Feb 2014).

indicates that

the Indigenous

mortality gap in

the NT should

close within a

generation

Coffey et al

progress made

in reducing

Indigenous

mortality rates

in the Northern

Territory ...

may reflect

improvements

in the social

determinants of

health

Russell

\section{Engaging Aboriginal and Torres Strait Islander men in primary care settings}

To The Editor: It is well recognised that Aboriginal and Torres Strait Islander men are one of the most disadvantaged population groups in Australia in terms of physical wellbeing. ${ }^{1}$ Annual Medicare Benefits Schedule health assessment items are essential tools to help Aboriginal and Torres Strait Islander men (and women and children) receive primary health care matched to their needs, as well as opportunities for preventive health care and education.

A growing body of evidence suggests that erectile dysfunction (ED) coexists with, or is a clinical marker for, common life-threatening conditions, such as coronary heart disease and type 2 diabetes, due to shared underlying neurovascular mechanisms. ${ }^{2}$ Indeed, the relative risk and severity of coronary artery disease appears to be higher for young men reporting ED. ${ }^{3}$ Despite this, discussion with Aboriginal and Torres Strait Islander men about sexual health is often lacking. In such population groups at risk of chronic disease, the opportunity to assess erectile function may present a window of opportunity to identify and better manage life-threatening disease. $^{2}$

To engage these men in sexual health discussions, a greater focus on culturally appropriate health services is needed. Cultural competency training is essential to overcome the barriers affecting how Aboriginal 
1 Factors influencing health service access and help-seeking behaviour for Aboriginal and Torres Strait Islander men ${ }^{4,5}$

\section{Societal}

- Illness-related stigma

- Sex-specific differences in health

Cultural

- Traditional gender-related law, masculinity and gender roles

- Language barriers

- Beliefs around causation

Logistical

- Lack of transport

- Conflict of appointment times with other family and community priorities (eg, ceremonies)

Health system

- Limited access to specialist services and/or treatment

- Complicated referral process

- Too few (male) health professionals, leading to patients seeing many different doctors

- Medical terminology and jargon

Financial

- Difficulties in meeting health service costs

\section{Individual}

- Knowledge or perception of the nature of the illness

Previous illness experience

- Low prioritisation of preventive health care

Lack of understanding and embarrassment

Low self-esteem and confidence

and Torres Strait Islander men access health services (Box 1). However, the sex-specific nature of some barriers and the impact of traditional and cultural roles on health service access pathways for men often require further attention, particularly for more culturally sensitive issues such as sexual health.

There are many other strategies and practical approaches that health services and primary health care professionals can implement to better engage Aboriginal and Torres Strait Islander men in positive and broader help-seeking behaviour and health service access (Box 2). ${ }^{6}$ Being able to implement such strategies may be an indirect reflection on the ability of health services to support cultural respect and provide culturally safe health care more broadly.

Mark Wenitong Public Health Medical Advisor, and Senior Aboriginal Public Health Medical Officer ${ }^{2}$

Michael Adams Research Fellow ${ }^{3}$
2 Examples of culturally appropriate strategies for engaging with Aboriginal and Torres Strait Islander men about sexual health issues

- Provide a safe, private and comfortable environment that supports open and free dialogue

- Men may not open up in the first consultation - take time to build trust and respect

- Encourage men to have annual health assessments and incorporate sexual health questioning into these

- Make the clinic conducive to talking about sensitive issues; for example, a model of the male pelvis in the consulting room might help initiate discussion

- If only female health care providers are available, approach gender-specific issues in a sensitive way and use male Aboriginal health workers for advice or, if not urgent, refer to a male general practitioner

Carol A Holden Chief Executive Officer ${ }^{4}$ 1 Apunipima Cape York Health Council, Cairns, QLD. 2 National Aboriginal Community Controlled Health Organisation, Canberra, ACT.

3 Centre for Health and Wellbeing, Australian Institute of Aboriginal and Torres Strait Islander Studies, Canberra, ACT.

4 Andrology Australia, School of Public Health and Preventive Medicine, Monash University, Melbourne, VIC.

carol.holden@monash.edu

Acknowledgements: We acknowledge and thank the members of the Andrology Australia Aboriginal and Torres Strait Islander Male Health Reference Group for their ongoing advice and contribution to our work in this area. The Andrology Australia program is supported by the Australian Government Department of Health. The department played no role in the writing of this letter.

Competing interests: No relevant disclosures. doi: 10.5694/mjal4.00160

1 Australian Institute of Health and Welfare. The health of Australia's males: a focus on five population groups. Canberra: AlHW, 2012. (AlHW Cat. No. PHE 160).

2 Schwartz BG, Kloner RA. Clinical cardiology: physician update: erectile dysfunction and cardiovascular disease. Circulation 2011; 123. 98-101.

3 Riedner CE, Rhoden EL, Fuchs SC, et al. Erectile dysfunction and coronary artery disease: an association of higher risk in younger men. J Sex Med 2011; 8: 1445-1453.

4 Wenitong M. Indigenous male health: a report for Indigenous males, their families and communities, and those committed to improving Indigenous male health. Canberra: Office for Aboriginal and Torres Strait Islande Health, Department of Health and Ageing, 2002.

5 Australian Bureau of Statistics and Australian Institute of Health and Welfare. The health and welfare of Australia's Aboriginal and Torres Strait Islander peoples 2005. Canberra: AlHW, 2005. (AlHW Cat. No. IHW 14.)

6 Andrology Australia. Engaging Aboriginal and Torres Strait Islander males. The Healthy Male 2013; (46): 3-4. https://www. andrologyaustralia.org/engaging-indigenousmales (accessed May 2014)
Crusted scabies: a

clinical marker of human

T-lymphotropic virus type 1 infection in central Australia

To THE Editor: Scabies continues to cause significant morbidity among residents of Indigenous communities. ${ }^{1}$ In the Northern Territory, scabies underlies most cases of Streptococcus pyogenes pyoderma, a major cause of poststreptococcal glomerulonephritis and rheumatic fever. ${ }^{1,2}$ The increased risk of scabies resulting from infection with the human T-lymphotropic virus type 1 (HTLV1) has received little attention. This human retrovirus is endemic to much of Western Australia,

Wenitong et al South Australia and the NT. In a recent study, $33 \%$ of nearly 1600 Indigenous adults tested at Alice Springs Hospital (ASH) were infected. ${ }^{3}$

We report the case of a 36-yearold HTLV-1-infected Indigenous man from an Alice Springs town camp who was admitted to ASH with severe crusted scabies. Since early childhood, he had been hospitalised six times with recurrent scabies and had also been admitted with intestinal strongyloidiasis and chronic suppurative lung disease. On examination, he had confluent areas of hyperkeratosis with profuse skin shedding, deep skin cracks, bleeding and ooze involving the lower half of his body (Box). Skin scrapings revealed numerous scabies mites. Full blood examination showed an eosinophilia $\left(2.6 \times 10^{9} / \mathrm{L}\right.$; reference interval [RI], $0-0.4 \times 10^{9} / \mathrm{L}$ ) and markedly elevated IgE levels $(177000 \mathrm{kU} / \mathrm{L} ; \mathrm{RI},<110 \mathrm{kU} / \mathrm{L})$. HTLV-1 infection was confirmed by western blot at the National Serology Reference Laboratory. The HTLV-1 proviral load was high, at 1.29 per 100 peripheral blood

Einsiedel et al mononuclear cells. High HTLV-1 proviral loads have been associated with strongyloidiasis and HTLV1-driven inflammatory diseases. ${ }^{4}$ Serological testing for Strongyloides was negative and no other cause of immunodeficiency was found. Treatment of household contacts and cleaning of accommodation proved 
PBS Information: Authority

Required (STREAMLINED).

Refer to PBS Schedule for full authority information. Acknowledgements: This work was supported by the grant 1012945) and the Northern Territory Rural Clinical School, an initiative of the Australian Government Department of Health and Ageing.

cracks, bleeding and ooze on the patient's thigh

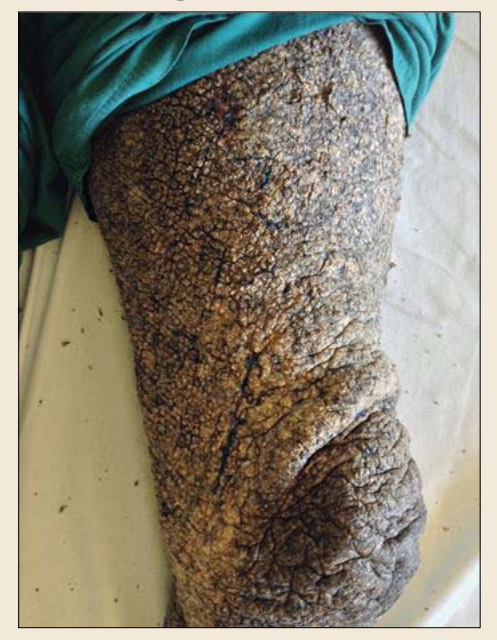

difficult due to resource limitations and the number of houses in which he stayed. Three weeks after discharge, a 41-year-old woman with HTLV-1 infection from the same town camp was admitted with typical scabies.

Crusted scabies is considered to be a clinical indicator of HTLV1 infection in HTLV-1-endemic areas. ${ }^{4,5}$ As in this case, re-infection and relapse are common, and failure to effectively manage core transmitters results in a cycle of infection that demoralises communities and carries the attendant risks of secondary bacterial infection. ${ }^{1,2}$ The risks of complications are particularly high in HTLV-1-endemic central Australia, where HTLV-1 infection is also associated with blood stream infections, strongyloidiasis, pulmonary disease, leukaemia, infective dermatitis and myelopathy. ${ }^{3}$ The growing number of lifethreatening sequelae that affect Indigenous Australians with HTLV-1 infection are a compelling reason to urgently implement a program to control HTLV-1 transmission among the Indigenous population of central Australia.

\section{Lloyd J Einsiedel Physician}

Clinton Pepperill Aboriginal Research Officer

Kim Wilson Senior Scientist ${ }^{2}$

1 Northern Territory Rural Clinical School, Flinders University, Alice Springs, NT.

2 National Serology Reference Laboratory, Melbourne, VIC. lloyd.einsiedel@nt.gov.au
Competing interests: No relevant disclosures. doi: $10.5694 / \mathrm{mjal} 4.00458$

1 Walton SF, Currie BJ. Problems in diagnosing scabies, a global disease in human and animal populations. Clin Microbiol Rev 2007; 20 : 268-279.

2 Roberts LJ, Huffam SE, Walton SF, Currie BJ. Crusted scabies: clinical and immunological findings in seventy-eight patients and a review of the literature. J Infect 2005; 50: 375-381.

3 Einsiedel L, Spelman T, Goeman E, et al. Clinical associations of human T-lymphotropic virus type 1 infection in an Indigenous Australian population. PLOS Negl Trop Dis 2014; 8: e2643.

4 Verdonck K, Gonzalez E, Van Dooren S, et al. Human T-lymphotropic virus l: recent knowledge about an ancient infection. Lancet Infect Dis 2007; 7: 266-281.

5 Mollison LC, Lo ST, Marning G. HTLV-l and scabies in Australian Aborigines. Lancet 1993; 341: 1281-1282.

\section{Partial foot amputations may not always be worth the risk of complications}

To THE EDITOR: In their recent article, Dillon and colleagues cite reports that the incidence of partial foot amputations is rising and that the functional outcome of these amputations is poor. ${ }^{1}$ They express difficulty in understanding "why the high risk of complications and secondary amputations associated with partial foot amputation do not weigh more heavily in decisions about amputation surgery". Finally, they propose that more transtibial than partial foot amputations should be considered to minimise the risk of complications and further amputation.

The authors' argument is misleading as they combine two very different entities, toe amputation and major forefoot amputation, as the single entity of "partial foot amputation". As their own work has shown, ${ }^{2}$ toe amputations make up $90 \%$ of all "partial foot amputations" and it is mainly toe amputations that are becoming more common. The evidence they cite about complications and poor outcomes in "partial foot amputations" is based exclusively on (less commonly performed) transmetatarsal and midfoot amputations, and not on toe amputations. While the early they combine

two very

different

entities, toe

amputation

and major

forefoot

amputation,

as the single

entity of

'partial foot

amputation'

Norman et al

(1)

PLEASE REVIEW THE FULL PRODUCT INFORMATION BEFORE PRESCRIBING. THE APPROVED PRODUCT INFORMATION IS AVAILABLE UPON REQUEST FROM BAYER AUSTRALIA LTD AND CAN BE ACCESSED AT WWW.BAYERRESOURCES COM.AU/RESOURCES/UPLOADS/PI/ FILE9466.PDF

Minimum Product Information, XARELTO ${ }^{\circledR}$ (rivaroxaban) INDICATIONS: Prevention of venous thromboembolism (VTE) in adult patients who have undergone major orthopaedic surgery of the lower limbs (elective total hip replacement, treatment for up to 5 weeks; elective total knee replacement, treatment for up to 2 weeks), $10 \mathrm{mg}$ tablet once daily. Prevention of stroke and systemic embolism in patients with non-valvular atrial fibrillation and at least one additional risk factor for stroke, $20 \mathrm{mg}$ tablet once daily (15 mg for patients with $\mathrm{CrCl} 30-49 \mathrm{~mL} / \mathrm{min}$ ). Treatment of deep vein thrombosis (DVT) and pulmonary embolism (PE)* and for the prevention of recurrent DVT and pulmonary embolism (PE), $15 \mathrm{mg}$ tablet twice daily followed by $20 \mathrm{mg}$ tablet once daily. See full PI for details. CONTRAINDICATIONS: Hypersensitivity to rivaroxaban or to any of the excipients, clinically significant active bleeding, lesions at increased risk of clinically significant bleeding and patients with spontaneous impairment of haemostasis, significant hepatic disease which is associated with coagulopathy, dialysis* or severe renal impairment with a creatinine clearance < $15 \mathrm{~mL} / \mathrm{min}$ for Xarelto $10 \mathrm{mg}$ or $<30 \mathrm{~mL} / \mathrm{min}$ for Xarelto $15 \mathrm{mg}$ and $20 \mathrm{mg}$, concomitant treatment with strong inhibitors of both CYP 3A4 and P-glycoprotein, Pregnancy, Lactation. PRECAUTIONS: Increased bleeding risk such as general haemorrhagic risk (see PI for list), bronchiectasis or history of pulmonary bleeding, renal impairment, hepatic impairment, surgery and interventions, spinal/epidural anaesthesia or puncture, patients with prosthetic valves (no clinical data), haemodynamically unstable PE patients or patients who require thrombolysis or pulmonary embolectomy*, lactose intolerance. INTERACTIONS WITH OTHER MEDICINES: Care to be taken if concomitantly used with medicines affecting haemostasis; concomitant administration with NSAIDs, platelet aggregation inhibitors, other anticoagulants. ADVERSE EFFECTS: Please refer to PI for a complete list. Very common and common adverse reactions $(\geq 1 \%)$ include post procedural haemorrhage, increased transaminases, gingival bleeding, constipation, diarrhoea, nausea, pyrexia, oedema peripheral, contusion, pain in extremity, headache, dizziness, haematuria, menorrhagia, epistaxis, haematoma, anaemia rectal haemorrhage, fatigue and ecchymosis, haemoptysis, pruritus, conjunctival haemorrhage, abdominal pain, dyspepsia gastrointestinal haemorrhage, syncope, hypotension, increased gamma-glutamyltransferase, tachycardia, abdominal pain vomiting, asthenia, wound haemorrhage, subcutaneous haematoma and rash. Less frequent but serious adverse reactions include urticaria, hypersensitivity, hyperglycaemia cerebral, cerebellar and intracranial haemorrhage, haemorrhagic transformation stroke, jaundice, eye haemorrhage and loss of consciousness. Pl last updated on 27 Jun 2013.

\section{"Please note changes in Product Information}

References: 1. PBS Schedule of Benefits, January 2014 http://www.pbs.gov.au/pbs/home, accessed January 2014 2. Xarelto Approved Product Information, 27 June 2013.

Bayer Australia Ltd. ABN 22000138 714, 875 Pacific Highway, Pymble NSW 2073

XARELTO ${ }^{\circledR}$ is a registered trademark of Bayer AG, Germany. BAY3524/L.AU.GM.01.2014.0248 


\section{BAYER \\ Xarelto}

p635 
morbidity of toe ( \pm metatarsal head) amputation is not insignificant, the late functional outcomes are likely to be more favourable than transmetatarsal or midtarsal amputation.

Our interpretation of the available evidence is that the rising incidence of "partial foot amputations" is driven by more toe amputations in the increasing number of people with type 2 diabetes. This preserves acceptable function and may be contributing to the decline in major amputations. We acknowledge that further research is needed to clarify the relationship between these diverging trends.

Paul E Norman Professor of Vascular Surgery, School of Surgery

Deborah E Schoen Podiatrist, Western Australian Centre for Rural Health

Lee Nedkoff Research Associate, Cardiovascular Research Group, School of Population Health

University of Western Australia, Perth, WA

lee.nedkoff@uwa.edu.au

Competing interests: No relevant disclosures. doi: 10.5694/mjal4.00506

1 Dillon MP, Fatone S, Morris ME. Partial foot amputation may not always be worth the risk of complications. Med J Aust 2014; 200 : 252-253.

2 Dillon MP, Kohler F, Peeva V. Incidence of lower limb amputation in Australian hospitals from 2000 to 2010. Prosthet Orthot Int 2014; 38 : 122-132.

To THE EDITOR: Dillon and colleagues present a challenging perspective on the evidence comparing partial foot amputation (PFA) and below-knee amputation (BKA) outcomes. ${ }^{1,2}$ Australia's diabetes-related major amputation rates have only recently reduced to international levels ${ }^{3}$ and we fear that any oversimplistic perspectives may be detrimental to these improved rates and, importantly, to our patients. Thus, we believe these articles ${ }^{1,2}$ should be read cognisant of some important points.

First, the authors correctly identify that $75 \%$ of Australia's amputations are PFAs (toe, ray or transmetatarsal amputations [TMAs]), ${ }^{4}$ yet base their PFA arguments nearly entirely on TMA literature. ${ }^{1,2}$ TMAs are complex procedures and make up just $5 \%-$ $10 \%$ of PFAs. ${ }^{4}$ Thus, we believe the article should be primarily read as a comparison between TMA and BKA outcomes.
Second, the authors correctly report higher ipsilateral reamputation risks for TMAs compared with BKAs; ${ }^{1,2}$ however, they omit lower contralateral amputation risks ${ }^{5}$ and somewhat dismiss well reported lower mortality risks. ${ }^{1,2,5}$

Last, the authors conclude "very similar functional outcomes" from data comparing methodologically different TMA studies with BKA studies or data within heterogeneous and underpowered studies. ${ }^{1,2}$ These definitive interpretations may be misleading, especially given the statistically significant functional benefits of TMAs compared with BKAs, as reported in the higher impact studies the authors cite. ., $^{2}$

We thank Dillon et al for highlighting such a large, yet silent, burden of disease and hope this letter will provide more balance to this crucial life-changing decision facing 8000 Australians and their clinicians this year. ${ }^{4}$

Peter A Lazzarini Senior Research Fellow ${ }^{1,2}$

Matthew Malone Head of Department ${ }^{3}$

Paul R Wraight Head of Department ${ }^{4}$

1School of Clinical Sciences, Queensland University of Technology, Brisbane, QLD.

2 Allied Health Research Collaborative, Metro North Hospital and Health Service, Brisbane, QLD.

3 High Risk Foot Service, Liverpool Hospital, Sydney, NSW. 4 Diabetic Foot Unit, Royal Melbourne Hospital, Melbourne, VIC.

Peter.Lazzarini@health.qld.gov.au

Competing interests: No relevant disclosures. doi: 10.5694/mja14.00476

1 Dillon MP, Fatone S, Morris ME. Partial foot amputation may not always be worth the risk of complications. Med J Aust 2014; 200: 252-253.

2 Dillon MP, Fatone S. Deliberations about the functional benefits and complications of partial foot amputation: do we pay heed to the purported benefits at the expense of minimizing complications? Arch Phys Med Rehabil 2013; 94: 1429-1435.

3 Organisation for Economic Co-operation and Development (OECD). Health Care Quality Indicators: Primary Care: Diabetes lower extremity amputation. France, OECD 2013. http://stats.oecd.org/index. aspx?DataSetCode=HEALTH_STAT (accessed Mar 2014).

4 Dillon MP, Kohler F, Peeva V. Incidence of lower limb amputation in Australian hospitals from 2000 to 2010. Prosthet Orthot Int 2014; 38: 122-132.

5 Izumi Y, Satterfield K, Lee S, Harkless LB. Risk of reamputation in diabetic patients stratified by limb and level of amputation: a 10-year observation. Diabetes Care 2006; 29: 566-570.

6 Kanade RV, van Deursen RW, Harding K, Price P. Walking performance in people with diabetic neuropathy: benefits and threats. Diabetologia 2006; 49: 1747-1754.
IN REPLY: We appreciate the opportunity to reply to two letters submitted in response to our article. ${ }^{1}$

Both letters agree that our perspective piece was mainly based on evidence about the outcomes for people with transmetatarsal amputation, noting that most people undergo amputation of the toe(s) or toes and metatarsals. As highlighted in our supporting work, ${ }^{2}$ there are comparatively few investigations focusing on outcomes for people with digital, ray, tarsometatarsal and transtarsal amputation. Despite this, we stand by our interpretation that the rates of complications and reamputation seem very similar across levels of partial foot amputation. ${ }^{1,2}$ To illustrate, a study that stratified

Lazzarini et al

large numbers of people by level of partial foot amputation found that the rates of ipsilateral reamputation were not statistically different in groups with either toe, ray or midfoot (ie, transmetatarsal, Lisfranc and Chopart) amputation. ${ }^{3}$ Given these data, we argue that our synthesis of published outcomes on the rates of reamputation and other complications for people with different levels of partial foot amputation was reasonable. Our article should not be considered a comparison between the outcomes of transmetatarsal and transtibial amputation.

We do not believe that current data show that toe amputations are becoming more common in Australia. The age-standardised incidence of toe amputation remained stable between 2000 and 2010, while the incidence of partial foot amputation at the toe and metatarsal level and transmetatarsal level increased. ${ }^{4}$

We are not advocating that more transtibial amputations should be considered to minimise the risk of complications and further amputations. Rather, clinicians should consider the emerging evidence when communicating the perceived benefits to patients; particularly given that this evidence challenges long-held beliefs. ${ }^{2}$

We are grateful for the opportunity to promote discussion and highlight awareness of the need for further research into outcomes 
for people facing difficult decisions about limb loss.

Michael P Dillon Senior Lecturer, National Centre for Prosthetics and Orthotics

\section{Stefania Fatone Associate Professor ${ }^{2}$}

Meg E Morris Professor, School of Allied Health ${ }^{1}$ 1 La Trobe University, Melbourne, VIC

2 Northwestern University Prosthetics-Orthotics Center, Northwestern University, Chicago, Ill, USA.

\section{Michael.Dillon@latrobe.edu.au}

Competing interests: No relevant disclosures. doi: 10.5694/mjal4.00629

1 Dillon MP, Fatone S, Morris ME. Partial foot amputation may not always be worth the risk of complications. Med J Aust 2014; 200: 252-253.

2 Dillon MP, Fatone S. Deliberations about the functional benefits and complications of partial foot amputation: do we pay heed to the purported benefits at the expense of minimizing complications? Arch Phys Med Rehabil 2013; 94: 1429-1435.

3 Izumi Y, Satterfield K, Lee S, Harkless LB. Risk of reamputation in diabetic patients stratified by limb and level of amputation: a 10-year observation. Diabetes Care 2006; 29: 566-570.

4 Dillon MP, Kohler F, Peeva V. Incidence of lower limb amputation in Australian hospitals from 2000 to 2010. Prosthet Orthot Int 2014; 38: 122-132.

\section{Off-label prescribing}

To the Editor: Off-label prescribing is a complex paradigm, with important clinical, safety, ethical, legal and financial dimensions. The articles by Seale, ${ }^{1}$ Hickie, ${ }^{2}$ and Harris and
Naylor ${ }^{3}$ highlight some associated controversies and the need for a rigorous approach.

The Council of Australian Therapeutic Advisory Groups (CATAG) has recently developed national guiding principles that provide a structured framework to support judicious, appropriate, safe, effective and cost-effective off-label use of medicines. ${ }^{4}$ This framework will facilitate a more rigorous and consistent approach to decision making by health professionals, consumers, and drug and therapeutics committees in their evaluation and use of medicines that are prescribed off label. CATAG's guidance provides an important expansion and update on previous Australian recommendations. ${ }^{5}$

There are seven overarching guiding principles, including a core principle of systematic evaluation of the evidence base and riskbenefit ratio for proposed off-label uses. Comprehensive advice for involving patients and carers in shared decision making and systematic outcomes evaluation is also provided. Applying these principles in routine practice will help address the clinical, safety and ethical concerns that have recently been highlighted. CATAG anticipates undertaking future work to support wider implementation of the guiding principles.

Madlen Gazarian Specialist Advisor and Co-Chair, Off-label Expert Advisory Group, and Honorary Associate Professor $^{2}$

\section{Steve Morris Chai}

CATAG

[provides] a

structured

framework

to support

judicious,

appropriate,

safe, effective

and cost-

effective off-

label use

of medicines

Gazarian et al
1 Council of Australian Therapeutic Advisory Groups, Sydney, NSW.

2 School of Medical Sciences, University of New South Wales, Sydney, NSW.

\section{M.Gazarian@unsw.edu.au}

Acknowledgements: CATAG is supported by funding from NPS MedicineWise, an independent not-forprofit public company funded by the Australian Government Department of Health. This funding is managed through a services agreement between NPS MedicineWise and the New South Wales Therapeutic Advisory Group, an independent, not-for-profit member-based organisation supported by the NSW Ministry of Health

Competing interests: No relevant disclosures. doi: 10.5694/mjal4.00577

1 Seale JP. Off-label prescribing. Med J Aust 2014; 200: 65.

2 Hickie IB. Reducing off-label prescribing in psychiatry. Med J Aust 2014; 200: 65-66.

3 Harris IA, Naylor, JM. Double standards in clinical practice ethics. Med J Aust 2014: 200: 76.

4 Council of Australian Therapeutic Advisory Groups. Rethinking medicines decision-making in Australian hospitals. Guiding principles for the quality use of off-label medicines. CATAG, 2013. http://www.catag.org.au/wpcontent/uploads/2012/08/OKA9963-CATAG Rethinking-Medicines-Decision-Making-final. pdf (accessed Mar 2014).

5 Gazarian M, Kelly M, McPhee JR, et al. Off-label use of medicines: consensus recommendations for evaluating appropriateness. Med J Aust 2006; 185: 544-548.

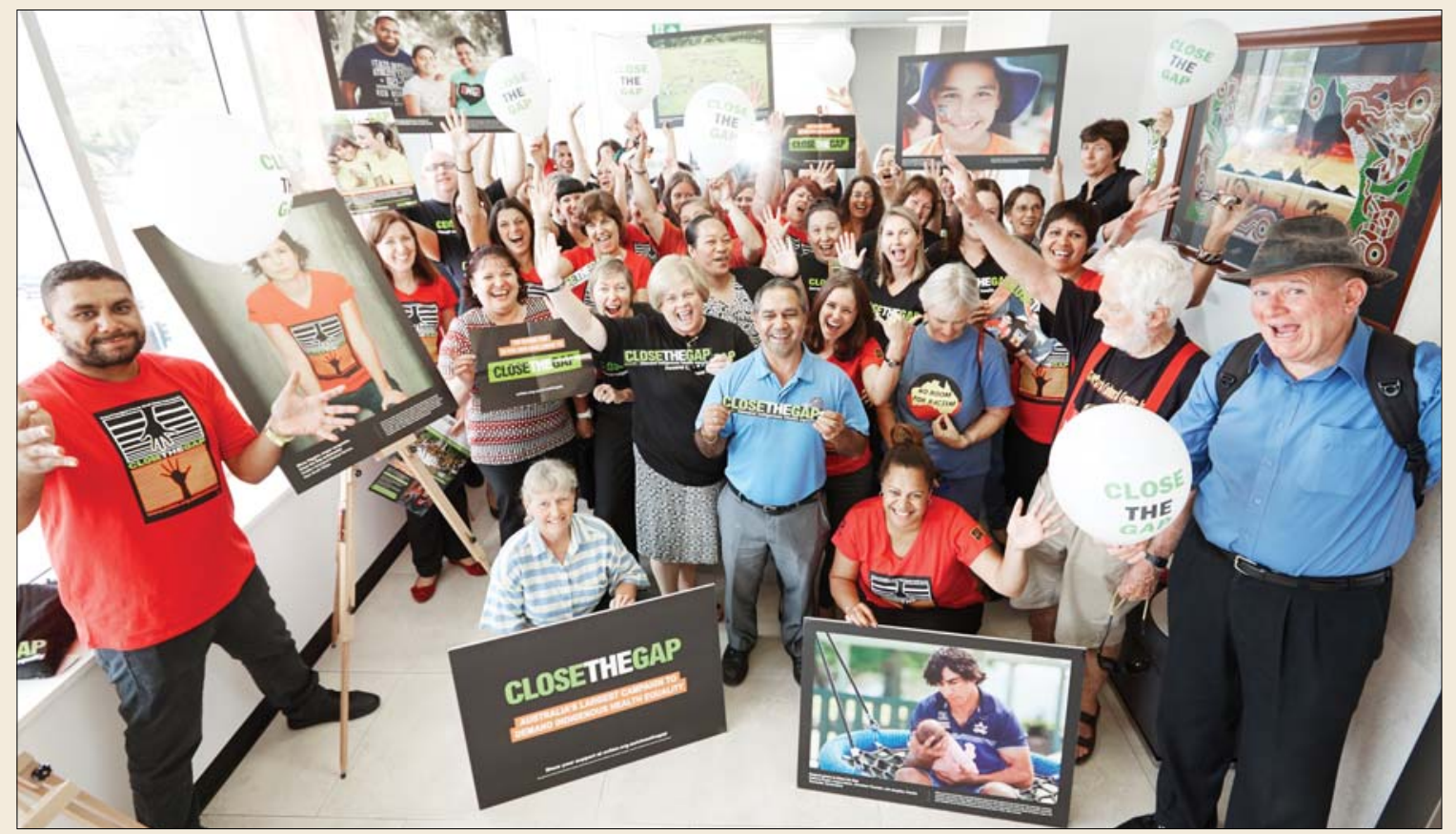

Close the Gap day morning tea 2014, hosted by Queensland Aboriginal and Islander Health Council and CHECKUP, with friends from OXFAM and ANTaR.

Photo credit: Jason Malouin 